\title{
The Promethean Fire of Cloning
}

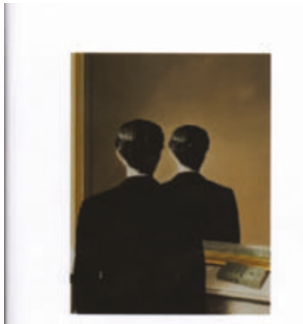

\section{A Clone of Your Own? The science and ethics of cloning}

by Arlene Judith Klotzko

Oxford University Press • 2004

$£ 12.99$

A Clone of Your Own?

\section{R. Alta Charo}

When South Korean researchers announced in early 2004 that they had successfully used somatic cell nuclear transfer to develop a blastocyst, the world press was electrified, and national debates on the ethics of cloning were reignited. But little in this latest incarnation of the debate differs from those that have dogged the technology since the announcement of Dolly in 1997 and subsequent announcements from the University of Wisconsin and The Johns Hopkins University of their success at deriving pluripotent immortalized stem cell lines from human embryos and foetal tissue.

Cloning involves the transfer of a somatic cell nucleus into an enucleated egg, a process that, when successful, causes the egg to divide as if it had been fertilized. The resulting blastocyst can be transferred to a uterus for development to birth - something performed in numerous mammalian species but not yet in humans - or the blastocyst can be used for embryo research.

Opponents continue to worry about the prospect of reproductive cloning, and fear that even basic laboratory research, although nonreproductive in its aims, will result in a cookbook for the would-be reproductive cloners. In addition, many of these opponents object strongly to the use of embryos in research - even if they are left over from fertility procedures and are destined to be discarded - and even more strongly to the deliberate creation of embryos solely for research purposes. However, supporters claim that the potential gains for basic research are so significant that it's necessary for us to protect the technology from those who would criminalize it for fear of reproductive uses that can be separately regulated or prohibited. The debate is a lively one, with numerous countries outlawing even basic research, whereas others regulate and promote the research applications but forbid reproductive applications. The UK is the best example of the latter approach, with Israel and the two US states of California and New Jersey following suit.

R. Alta Charo, University of Wisconsin Law School, University of Wisconsin, 975 Bascom Mall, Madison, WI 53706, USA. E-mail: racharo@facstaff.wisc.edu
Arlene Judith Klotzko's book, although published in 2004, has already become somewhat dated with regard to the scientific developments, as it was published before the announcement of the South Korean research. But its breezy romp through the history of the cloning debate remains timely, helping readers to understand how we arrived at today's confused situation, whereby some countries, such as Italy, are on the verge of enacting draconian restrictions on all reproductive technologies and stem cell research, whereas others actively promote, regulate and even fund them.

For the scientist wishing to learn more about the issues surrounding this technology, for the college student or for the casual observer, Klotzko's book provides an excellent introduction to the science, ethics and politics of the history of embryo research and cloning. It also well outlines the pitfalls and possibilities, discussing at length the distinction between reproductive uses dogged by fears of birth defects and social disruption, and research uses holding promise for basic research or even transplantation of immuno-matched tissue for those with degenerative diseases. It does, alas, repeat the claim that the primary benefit of cloning may be in the realm of autologous transplantation. Although this is indeed what excites patient groups, it is the use of cloning to develop stem cells, and then tissues with specific mutations, that excites doctors and scientists seeking cures to genetic diseases.

But Klotzko's book is not for sophisticated observers of this debate, nor does it seem to aspire to reach this audience. Its tone is lighthearted, and although it refers to current debates about the moral status of the embryo or the ethics of reproductive cloning, it does not attempt a scholarly analysis. Nor does it purport to survey the political terrain thoroughly. It gives only scant coverage of the collateral debates within the feminist community over how to reconcile opposition to eugenics (or concern over female egg donors with their overall commitment to reproductive autonomy) and to ensuring that embryos not be given moral priority over adults. Neither does it examine the role of the Green Party and the environmentalist movements that have, in the context of their scepticism towards much of biotechnology, at times led the argument against even non-reproductive uses of cloning. And although it gives a good account of the debates within the UK, it pays relatively little attention to debates within the USA, the European Union, or the non-Christian countries, such as India and Singapore, where work is proceeding with little of the standard debate about "playing god."

In a recent piece for the San Francisco Chronicle, writer David Ewing Duncan wrote of the creative fire that is cloning:

"In the ancient Greek myth, the god Prometheus brought fire to human beings in defiance of a ban by Zeus.... The tale underscores the dual nature of scientific discovery - that fire is a potent tool for improving life but can also be a force of destruction."

One of the greatest challenges to the responsible development of science is the ignorance exhibited by many members of the public, who are are called upon to vote for legislators who will set the policies that will nurture or smother the fires of cloning. Klotzko's book is therefore a welcome addition to existing resources for the lay public (and the scientist audience) and one hopes it will help the public decide to keep the fires burning. 